\title{
Microstructure and crystallization mechanism of Ti-based bulk metallic glass by electron beam welding
}

\author{
Gang Wang ${ }^{\mathrm{a}, \mathrm{b}^{*}}$, Yongjiang Huang ${ }^{\mathrm{c}}$, Wei Cao ${ }^{\mathrm{b}}$, Zhongjia Huang ${ }^{\mathrm{a}}$, Marko Huttula ${ }^{\mathrm{b}}$, \\ Yongsheng $\mathrm{Su}^{\mathrm{a}}$, Caiwang, $\operatorname{Tan}^{\mathrm{c}}$
}

\begin{abstract}
a School of Mechanical and Automotive Engineering, Anhui Polytechnic University, Wuhu 241000, PR China

b Nano and Molecular Systems Research Unit, University of Oulu, P.O. Box 3000, FIN-90014, Oulu, Finland

c State Key Laboratory of Advanced Welding and Joining, Harbin Institute of Technology, Harbin 150001, PR China
\end{abstract}

${ }^{*}$ Corresponding author: School of Mechanical and Automotive Engineering, Anhui Polytechnic University, Wuhu 241000, PR China

E-mail: gangwang@ahpu.edu.cn (G. Wang).

Abstract

In this work, we report on the successful welding of the Ti-based bulk metallic glass (BMG) plates via electron beam welding route. Microstructure determination shows that crystalline phases exist both in weld zone (WZ) and heat affected zone (HAZ). The critical cooling rate for glass formation in $\mathrm{WZ}$ is depended on the solidification condition. The continuous heating transformation curve (CHT) of glass transition temperature $\left(T_{g}\right)$ and crystallization temperature $\left(T_{x}\right)$ during heating process, time-temperature-transformation diagram (C-curve) during cooling process, and the thermal cycle curves are obtained by Kissinger equation, nucleation theory, and temperature field simulation, respectively. The crystallization mechanism in HAZ was discussed in details during the heating and cooling processes. The intersection between cooling curve and C-curve denotes the crystallization of HAZ during the cooling process.

Keywords: Bulk metallic glass; Electron beam welding; Weld zone; Heat affected zone 


\section{Introduction}

Due to the disordered atomic structures inherited from molten melts, bulk metallic glasses (BMGs) are normally endowed with unusual physical, mechanical, and chemical properties superior to those of their crystalline counterparts. With high hardness, excellent corrosion resistance, superior strength, and high elastic limit, the BMGs are promising for multifunctional applications in different industries [1]. However, their three-dimensional (3D) size is limited within only tens of millimeters, yet, severely hindering the industrial applications of BMGs [2]. Thus, it is crucial to find a route to form bigger BMGs in order to enable them as structural materials.

To date, numerous efforts have been devoted to increase the 3D size of BMGs, including optimization of chemical composition and preparation technology, welding and 3D print process [3-9]. High energy beam welding, as a modern welding process, has been widely used because of its advantages such as deep welding penetration, high welding energy density, and little deformation and so on [10]. Yokoyama et al. connected the Zr-based metallic glass using a conventional electron-beam welding process [11]. Similarly, the Zr-based metallic glasses were tightly wielded by using a focused fiber laser beam [12]. Shen et al. successfully welded $\mathrm{Ti}_{40} \mathrm{Zr}_{25} \mathrm{Ni}_{3} \mathrm{Cu}_{12} \mathrm{Be}_{20}$ BMG together by laser welding process, and found that the tensile strength of the welded sample can reach up to $93 \%$ of the base material [13]. Tsumaura et al. investigated dissimilar joining of Ni-based metallic glass to stainless steel by fiber laser beam [14]. Despite of these experimental studies, mechanisms towards crystallization kinetics and thermal stability have been scarcely reported. Chen et al. researched the crystallization behaviors of Zr-based BMG by Kissinger analysis and temperature field simulation [15]. Sun et al. demonstrated the spherulitic crystallization mechanism of BMG by activation energy and nucleation theory [16]. Lu et al. studied the crystallization of a Zr-based BMG during laser 3D printing process based on the thermal cycle curves obtained from finite element method (FEM) analysis [17]. It should be noticed that the crystallization mechanism in the aforementioned works has been only interpreted during either heating or cooling 
process. Therefore, it is necessary to propose an integral and effective method for crystallization analysis in both the heating and cooling processes.

In the present work, we used electron beam to weld the $\mathrm{Ti}_{40} \mathrm{Zr}_{25} \mathrm{Ni}_{3} \mathrm{Cu}_{12} \mathrm{Be}_{20}$ BMG. The microstructure in the weld zone (WZ) and heat affected zone (HAZ) was studied in details. The continuous transformation heating curve (CHT) during heating process and time-temperature-transformation diagram (C-curve) during cooling process were obtained by Kissinger equation and nucleation theory. Also, the thermal cycle curves with different welding parameters were obtained by temperature field simulation. By combining these curves, the crystallization mechanisms in HAZ were proposed for both heating and cooling process.

\section{Experimental}

The quinary $\mathrm{Ti}_{40} \mathrm{Zr}_{25} \mathrm{Ni}_{3} \mathrm{Cu}_{12} \mathrm{Be}_{20}$ alloy ingots were prepared by arc melting $\mathrm{Ti}, \mathrm{Zr}$, $\mathrm{Ni}, \mathrm{Cu}$, and $\mathrm{Be}$ metals with purities above $99.9 \%$ and drop casting into a copper mould in a Ti-gettered argon atmosphere. The obtained plate-shaped samples had a dimension of $3 \mathrm{~mm} \times 30 \mathrm{~mm} \times 50 \mathrm{~mm}$. The glassy nature of the as-cast samples was confirmed by X-ray diffraction analysis. The electron-beam welding was carried out in a vacuum of $5 \times 10^{-3} \mathrm{~Pa}$. The accelerate voltage was $150 \mathrm{kV}$ and the focus current was $2057 \mathrm{~mA}$. The welding beam current was $16 \mathrm{~mA}$. The welding speeds ranged from $28 \mathrm{~mm} / \mathrm{s}$ to $34 \mathrm{~mm} / \mathrm{s}$, respectively. The ratio of the focal length and distance from specimen surface to electron lens, $a_{b}$ value, was selected to be 1. After welding, microstructure observations were conducted by scanning electron microscopy (SEM, Quanta 200FEG), transmission electron microscopy (TEM, Tecnai G2 F30), and micro-area X-ray diffraction (Bede D1). The TEM samples were prepared by mechanical polishing, followed by twin-jet electropolishing. Thermal analysis was performed using differential scanning calorimetry (DSC) with a flow of purified argon gas. The viscosity of the Ti-based BMG with dimension of $4 \mathrm{~mm} \times 4 \mathrm{~mm} \times 55 \mathrm{~mm}$ was measured by three point bending viscometer containing a two-color Raytek pyrometer to accurately measure the temperature. Eq.1 shows the equation for the viscosity measurement via the three-point bending. 


$$
\eta=-\frac{g L^{3}}{2.4 I_{c} v}\left(M+\frac{\rho A L}{1.6}\right)
$$

Here $g$ is the acceleration of gravity; $I_{c}$ is the instantaneous inertia of cross section; $v$ is the rate of deformation of sample; $M$ is the applied weight; $\rho$ is the density of sample; $A$ is cross sectional area; $L$ is the distance between pivot.

A FEM analysis was used to calculate the thermal cycle. During the computation, a composite heat source containing plane heat source on the top surface and body heat source was used to simulate the high-energy beam source. The model used in present work was verified by previous work [13]. The equation of the model is shown as follows [18],

$$
\text { Plane heat source: } \quad q\left(r_{1}\right)=\frac{3 Q}{\pi r_{0}{ }^{2}} \exp \left(-\frac{3 r_{1}^{2}}{r_{0}^{2}}\right)
$$

The $q(r)$ is the surface heat flux when the radius is $r, \mathrm{Q}$ ithe input power; $\mathrm{r} 0$ the characteristic radius of heat flux distribution, and $r$ distance from the center of heat resource.

Body heat source reads: $q\left(r_{2}, h\right)=\frac{\beta \phi_{v}}{2 \pi r_{0}^{2} H} \exp \left(\frac{\beta r_{2}}{r_{0}}\right)\left(\frac{m h+r_{0}}{r_{0}}\right)$,

where $h$ is the distance between heat position and weld surface, $B$ the coefficient of energy, $\varphi_{v}$ the input power, $\mathrm{r}_{0}$ the radius of heat source, $H$ the depth of body heat source, and $M$ the coefficient of energy attenuation.

\section{Results and discussion}

Fig. 1a shows the external appearance of the sample welded by the different parameters. Welds can be clearly observed at the interface of the welded samples. No visible welding defects can be found from the view of appearance. Fig.1b-1d show the corresponding SEM images obtained from the fusion zone of welded BMG samples with different welding speeds. It can be seen that there are numerous crystalline phases in fusion zone, and exists the obvious interface between $\mathrm{WZ}$ and HAZ at 
different welding speeds. For different welding speeds, the crystalline phases are similar. The WZ consists of numerous flower-like crystals whereas HAZ contains many irregular polygon-like crystals. Meanwhile, no visible defects, pores or cracks are observed in both the WZ and HAZ, demonstrating a sound joint.

In order to further investigate the microstructure of joint, the microstructure of the joint from the middle of WZ to HAZ is studied. Fig.2 shows the SEM images of welded Ti-based joint with a welding speed of $34 \mathrm{~mm} / \mathrm{s}$. Fig.2a demonstrates the SEM images in the middle of WZ. A homogeneous and featureless characteristic was detected in the middle of weld, suggesting that no obvious devitrification occurs in the middle of joint. The average width of crystallization area in the WZ is measured to be $\sim 200 \mu \mathrm{m}$, as shown in Fig.2b. Fig.2c shows the microstructure of fusion zone between the WZ and HAZ, as similar to the Fig.1. An obvious interface can be found between the two zones, as indicated by the dotted line. Irregular polygon-like crystals with an average size of $\sim 1 \mu \mathrm{m}$ embedded in the HAZ were observed, as shown in Fig.2d. Fig.2e demonstrates the existence of many flower-like crystals with an average size of $5 \sim 10 \mu \mathrm{m}$ embedded in weld zone.

Figure 3 depicts the bright field TEM micrographs and corresponding selected area electron diffraction (SAED) patterns obtained from the middle of joint, $\mathrm{WZ}$ and HAZ with a welding speed of $34 \mathrm{~mm} / \mathrm{s}$. In the middle of joint, many nano-crystals with an average size of $\sim 200 \mathrm{~nm}$ were detected by TEM (Fig.3a). Fig.3b and Fig.3c show the TEM images of the WZ and HAZ. The strong diffraction spots in the inset of Fig. $3 \mathrm{~b}$ can be identified as $\mathrm{Ti}_{2} \mathrm{Ni}$ phase. The inset of Fig. $3 \mathrm{c}$ shows the SAED pattern taken from a crystal in HAZ. The strong diffraction spots belong to $\mathrm{Zr}_{2} \mathrm{Ni}$ phase.

Figure 4 shows the micro-focused XRD patterns obtained from the joint of the welded BMG. The interval between two scanning location was $\sim 300 \mu \mathrm{m}$. Inconspicuous but detectable diffraction of crystalline phases was observed in region A, which indicates the formation of nanocrystalline phase, consistent with the TEM observations. However, for fusion zone, the diffraction peaks were clearly observed in region $\mathrm{B}$ of the welded sample. The results show that there is a mixture of $\mathrm{Zr}_{2} \mathrm{Ni}$ and 
$\mathrm{Ti}_{2} \mathrm{Ni}$ phases. For region $\mathrm{C}$, there are also obvious diffraction peaks, and can be indexed to the $\mathrm{Zr}_{2} \mathrm{Ni}$ phases. Furthermore, diffraction pattern consisting of a broad halo appears in region $\mathrm{D}$, suggesting the existence of only glassy phase for the matrix.

A welded joint made by fusion welding consists of weld zone, fusion zone (line), heat affected zone, and base metal. For base metal, the microstructure almost remains unchanged after welding. Therefore, the quality of the welded joint depends on the microstructure of WZ and HAZ. The weld zone is the portion of the joint subjected to melting during welding. After welding, rapid cooling of the welded metal occurs. Thus, for metallic glass, the cooling rate from the liquidus temperature to the room temperature plays a crucial role on the microstructure of the WZ. A simplified cooling rate calculation in WZ was performed by Rosenthal [19] by the following equation,

$$
\mathrm{R}=\mathrm{k}\left(T-T_{0}\right)^{3}
$$

Here, $R$ is the cooling rate $(\mathrm{K} / \mathrm{s}) ; T$ is temperature of each point $(\mathrm{K})$; and $T_{0}$ the initial temperature, defined as $293 \mathrm{~K}$. The factor $k$ is defined as following:

$$
k=2 \pi \lambda \rho c\left(v_{w} s / q\right)^{2}
$$

In the equation, $\lambda$ is the thermal conductivity $(\mathrm{W} / \mathrm{m} \cdot \mathrm{K}) ; \rho$ is the density of material; $c$ is the specific heat $(\mathrm{J} / \mathrm{g} \cdot \mathrm{K}) ; v_{w}$ is the welding speed $(\mathrm{m} / \mathrm{s}) ; \mathrm{s}$ is the thickness of sample; and $q$ the heat input. In the present work, the value of $q$ can be calculated by the product of acceleration voltage and beam current of as $q=150 \times I_{b}$. Also, the value of $T$ is defined as $T_{m}$. The value of $\lambda, \rho, c$ and $T_{m}$ can be obtained from Ref. [20]. Combing Eq. 2 and Eq. 3 yields the cooling rate in the weld zone as follows:

$$
\mathrm{R}=8.4 \times 10^{-8}\left(\frac{\mathrm{v}_{w}}{I_{b}}\right)^{2}\left(T-T_{0}\right)^{3}
$$

Accordingly, a high cooling rate can be obtained by using high welding speed and small heat input. For the present work, $R$ is calculated to be $84 \mathrm{~K} / \mathrm{s}, 110 \mathrm{~K} / \mathrm{s}$ and 124 $\mathrm{K} / \mathrm{s}$ for the welding speed of $28 \mathrm{~mm} / \mathrm{s}, 32 \mathrm{~mm} / \mathrm{s}$ and $34 \mathrm{~mm} / \mathrm{s}$, respectively. Huang et $a l$. reported that the critical cooling rate $\left(R_{C}\right)$ of arc-melted $\mathrm{Ti}_{40} \mathrm{Zr}_{25} \mathrm{Ni}_{3} \mathrm{Cu}_{12} \mathrm{Be}_{20} \mathrm{BMG}$ is $\sim 3.2 \mathrm{~K} / \mathrm{s}$ [21], which is much smaller than the present values. Therefore, theoretically, the WZ of the joint prepared with the used parameters in the present 
work can lead to amorphous states. Actually, a large amount of flower-like crystals in WZ was detected by SEM and TEM, as shown in Fig.1-Fig.3. This is due to two aspects. On one hand, for metallic glass, the cooling rates in the joint not only strongly depend on the welding speed and heat input, but also on the thermo-physical parameters, especially the thermal conductivity $(\lambda)$, specific heat $(c)$, viscosity $(\eta)$ and so on. Furthermore, $\lambda, c$ and $\eta$ significantly vary with the temperature during heating and cooling process. Thus, the results calculated from Eq.4 may not abide by actual situation. Moreover, a higher welding speed can cause a longer WZ along welding direction under a constant heat input. The longer WZ can result in a lower cooling rate in the WZ. Thus, a fast welding speed and a small heat input do not always lead to a high cooling rate. On the other hand, the critical cooling rate for glass formation largely depends on the solidification condition. For $\mathrm{Zr}_{60} \mathrm{Cu}_{15} \mathrm{Ni}_{10} \mathrm{Al}_{10} \mathrm{Pd}_{5}$ metallic glass, Inoue et al. have reported a critical cooling rate of $\sim 190 \mathrm{~K} / \mathrm{s}$ for glass formation prepared by zone-melted method [22]. However, the critical cooling rate for glass formation is $\sim 40 \mathrm{~K} / \mathrm{s}$ under unidirectional solidification with a moving velocity of liquid/solid interface, $v$, of faster than $4 \mathrm{~mm} / \mathrm{s}$ and a temperature gradient, $G$, of greater than $4 \mathrm{~K} / \mathrm{mm}$ [23]. Besides, the critical cooling rate has been reported to be $110 \mathrm{~K} / \mathrm{s}$ obtained from the thermal analysis data of the cast melt in a wedge-shape copper mold [24]. That is, the critical cooling rate varies significantly from 40 to 190 $\mathrm{K} / \mathrm{s}$, whereas the alloy remains the same compositions. Drehman and Greer have proposed that there are some crystal growth centers called quenched-in nuclei in the glass-forming melt. Considering heterogeneous nucleation of a crystalline phase, the existence of quenched-in nuclei can lead the C-curve to shorter nose time [25]. This means that the higher critical cooling rate is required to achieve amorphous structure. The more quenched-in nuclei causes the shorter nose time [26]. Thus, the significant difference in $R_{c}$ can be attributed to the difference in the amount of quenched-in nuclei in the molten alloy resulting from the difference in the purity of the alloy melt and the atmosphere [27, 28]. According to our previous results [13], the critical cooling rate of $\mathrm{WZ}$ is at least $780 \mathrm{~K} / \mathrm{s}$ by melting welding, much higher than the critical cooling rate of arc-melted $\mathrm{Ti}_{40} \mathrm{Zr}_{25} \mathrm{Ni}_{3} \mathrm{Cu}_{12} \mathrm{Be}_{20} \mathrm{BMG}$ and the cooling rate in 
the present work. Therefore, for the present work, some crystalline phases form in the WZ.

The HAZ, a region adjacent to the WZ, has not been welded but has experienced a change in microstructure or mechanical properties due to the effects of heating and cooling during welding process. Here, the $\mathrm{CHT}$ curve and C-curve were established to interpret the crystallization behaviors of welded $\mathrm{Ti}_{40} \mathrm{Zr}_{25} \mathrm{Ni}_{3} \mathrm{Cu}_{12} \mathrm{Be}_{20}$ BMG. For continuous heating transformation curve, Kissinger equation can be introduced, which reflects the glass transition and crystallization behaviors during heating process, as follows [29]:

$$
\operatorname{In}\left(\frac{\mathrm{B}}{\mathrm{T}^{2}}\right)=-\frac{E}{R T}+\text { constant }
$$

Here, $B$ is the heating rate; $T$ is the specific temperature; $R$ is the gas constant; and $E$ is the activation energy. By using the values of the glass transition temperature $\left(T_{g}\right)$, crystallization temperature $\left(T_{x}\right)$ and $B$ indicated from the inset of Fig.5a, plots of $\operatorname{In}\left(B / T^{2}\right)$ against $1 /(R T)$ yield approximately straight lines as shown in Fig. 5a. $B$ can be approximatively defined as $(T-293) / t$, where $t$ is the heating time. Thus, the Kissinger equation in the characteristic temperatures can be described as:

$$
\begin{aligned}
& \operatorname{In}\left(\frac{\mathrm{T}_{\mathrm{g}}-293}{\mathrm{~T}_{\mathrm{g}}{ }^{2} \mathrm{t}}\right)=-\frac{26747}{T_{\mathrm{g}}}+33.5 \\
& \operatorname{In}\left(\frac{\mathrm{T}_{\mathrm{x}}-293}{\mathrm{~T}_{\mathrm{x}}{ }^{2} \mathrm{t}}\right)=-\frac{27108}{T_{x}}+31.4
\end{aligned}
$$

Based on Eq. 6 and Eq. 7 and $T_{g}, T_{x}$ values given by DSC (in the inset of Fig.5a), the continuous heating curves can be achieved, as shown in Fig.5b. It also shows the minimum heating time needed, i.e. the maximum heating rate with different welding parameters in order to avoid the crystallization during heating process. During the heating process, in order to achieve the amorphous state of joint, the thermal cycle curves should not intersect with the CHT curves, especially the CHT curve of $T_{x}$. This method can be used to predict the crystallization or beyond the heating process.

Next, the crystallization behavior during cooling process will be discussed. The Onorato-Uhlmann expression introduces formal transformation theory into the kinetic 
analyses for glass formation. Equation to calculate the homogeneous nucleation rate $I$ reads $[30,31]$ :

$$
I=\frac{N k T}{3 \pi a_{0}^{3} \eta} \exp \left(-\frac{1.229}{T_{r}^{3} \Delta T_{r}^{2}}\right)
$$

Here, $N$ is the number of single molecules per unit volume and is calculated to be 6.33 $\times 10^{26}$ atom $/ \mathrm{m}^{3}$ using the measured density of $5600 \mathrm{~kg} / \mathrm{m}^{3}$ for the studied alloy. $k$ is the Boltzmann constant, $a_{0}$ is the mean atomic diameter $\left(a_{0}=0.22 \mathrm{~nm}\right.$, calculated as the weighted average atomic diameter of the five components in the studied alloy) and $\eta$ is the viscosity. The reduced temperature $T_{r}$ is given by $T / T_{m}$, and $\Delta T_{r}$ is equal to $\left(T_{m}\right.$ $-T) / T_{m}$. The temperature-dependent viscosity is described with the empirical VFT equation [32]:

$$
\eta=\eta_{0} \exp \left(\frac{D^{*} T_{0}}{T-T_{0}}\right)
$$

where $\eta_{0}=N_{A} \cdot h / V, T_{0}$ is the VFT temperature at which the viscosity approaches infinity, $D^{*}$ is the fragility parameter, $N_{A}$ is Avogadro's constant, $h$ is Planck's constant, and $V$ is the molar volume. In the present study, based on the experimental data from our previous work [33], the value of $D^{*}$ and $T_{0}$ can be calculated to 13 and $426 \mathrm{~K}$, respectively.

The temperature dependence of the crystal growth rate $u$ can be expressed as [34]:

$$
u=\frac{f k T}{3 \pi a_{0}^{2} \eta}\left[1-\exp \left(-\frac{\Delta T_{r} \Delta H_{m}^{f}}{R T}\right)\right]
$$

where $f$ is the fraction of sites at the interface where growth occurs (here $f \approx 0.04$ ), and $\Delta H_{m}^{f}$ is the molar heat of fusion $\left(\Delta H_{m}^{f}=7209 \mathrm{~J} / \mathrm{mol}\right.$ in the present alloy[35]). Moreover, the Johnson-Mehl-Avrami equation [36] has been used to understand the crystallization kinetics of a glass, which gives the volume fraction of crystallized material $X$ as:

$$
X=1-\exp \left[-\frac{\pi}{3} I u^{3} t^{4}\right]
$$

where $t$ is the time taken to transform $X$. At the beginning of transformation or for a 
small $X$, Eq. 11 can be simplified to,

$$
X=\frac{\pi}{3} I u^{3} t^{4}
$$

From the Eq.12, for a fixed $X, t$ can be estimated as a function of temperature because $I$ and $u$ are expressed as a function of temperature. Therefore, a C-curve can be obtained. Combining Eqs.8-10, the temperature dependences of $I$ and $u$ are shown in Fig. 6a. The maximum growth rate is observed at $935 \mathrm{~K}, 50 \mathrm{~K}$ below the melting point of the studied alloy. The maximum nucleation rate is located at $680 \mathrm{~K}$, slightly higher than its crystallization temperature. A crystallized volume fraction $X=10^{-6}$ was identified as a just-detectable concentration of crystals which must be avoided if a glass is to be formed. The C-curve was estimated, as shown in Fig.6b.

A finite element analysis was employed to calculate the thermal cycle curves in the HAZ with the location near the fusion zone at different welding conditions, as shown in Fig.6b. A magnified image of intersection area between CHT curves and thermal cycle curves is shown in Fig.6c, as indicated by circle in Fig.6b. It can be seen that no intersection points exists between CHT curve of $T_{g}$ and thermal cycles curves with welding speeds of $32 \mathrm{~mm} / \mathrm{min}$ and $34 \mathrm{~mm} / \mathrm{min}$, revealing that the alloy still maintains glassy nature during heating process for high welding speed. However, for the welding speed of $28 \mathrm{~mm} / \mathrm{min}$, the thermal cycle curve intersects with the CHT curve of $T_{g}$, but not with the CHT curve of $T_{x}$. Due to the excellent thermal stability in supercooled liquid region and the short exposure time in this region, it is concluded that no crystallization takes place during heating process in this welding parameter.

Fig. 6d shows the magnification image of intersection area between thermal cycle curves and C-curve, as indicated by frame form Fig.6b. It can be seen that all the thermal cycle curves intersect the $\mathrm{C}$-curve during the cooling process. This suggests that the alloys are crystallized. The cooling curves can be divided into two parts. Due to its high-density energy applied to a localized area, electron beam welding would produce larger temperature gradient in HAZ, which would give rise to fast heat transfer and thus the rapid temperature drop during the beginning stage of cooling. The thermal conductivity and thermal diffusivity show a positive temperature 
coefficient for an amorphous solid [37, 38]. Therefore, upon further cooling, the thermal conductivity and thermal diffusivity gradually decrease, accompanied with the fast decrease in temperature gradient, causing the slow cooling rate during the final stage of cooling for HAZ. In the present work, for low welding speed as 28 $\mathrm{mm} / \mathrm{min}$ and $32 \mathrm{~mm} / \mathrm{min}$, intersection points exist between thermal cycle curves and C-curve during the slow cooling rate stage, as shown in Fig.6c. For a higher welding speed as $34 \mathrm{~mm} / \mathrm{min}$, intersection points exist between thermal cycle curves and C-curve during the fast cooling rate stage as shown in Fig.6c. Thus, a higher speed is required for the formation of glassy nature. However, the high welding speed causes the long melt region along welding direction under the constant heat input, leading the decease of cooling rate in the fast cooling rate stage, which is also harmful to the formation of metallic glass. Consequently, it is concluded that the BMG's welding demands the balance between the welding speed and heat input to obtain the satisfactory welded structure.

\section{Conclusions}

In summary, the electron beam welding was performed to join the $\mathrm{Ti}_{40} \mathrm{Zr}_{25} \mathrm{Ni}_{3} \mathrm{Cu}_{12} \mathrm{Be}_{20} \mathrm{BMG}$ samples. The microstructure shows that there are many $\mathrm{Zr}_{2} \mathrm{Ni}$ and $\mathrm{Ti}_{2} \mathrm{Ni}$ phases precipitated in $\mathrm{HAZ}$ and $\mathrm{WZ}$, respectively. The critical cooling rate for glass formation in WZ depends on the solidification condition, resulting from the purity of the alloy melt and the atmosphere. We estimated the CHT curve, C-curves and thermal cycle curves of the welded Ti-based BMG. The crystallization mechanism was analyzed based on the obtained curves. For HAZ, there are no intersection points between the CHT curves and thermal cycle curves, indicating that the HAZ remains amorphous nature in the heating process. However, the thermal cycle curves intersect with the C-curve, demonstrating that the crystallization of HAZ takes place in the cooling process.

\section{Acknowledgement}

This work was supported by the Key Research and Development Plan of Anhui 
Province [Grant No 1704a0902056], National Natural Science Foundation of China

[Grant No 51704001] and the Open Fund of State Key Laboratory of Advanced

Welding and Joining [Grant Nos AWJ-16-M04 and AWJ-16-Z02].

\section{Reference}

[1] W.L. Johnson, Bulk Glass-Forming Metallic Alloys: Science and Technology. MRS Bull 1999; 24: 42-56.

[2] Q.J. Chen, H.B. Fan, J. Shen, et al. Critical cooling rate and thermal stability of Fe-Co-Zr-Y-Cr-Mo-B amorphous alloy, J Alloys Compd 2006; 407: 125-128.

[3] Y.J Huang, P. Xue, S. Guo, et al. Liquid-solid joining of bulk metallic glasses. Sci Rep 2016; 6: 1-6.

[4] L. Shao, A. Datye, J.K Huang, et al. Pulsed laser beam welding of $\mathrm{Pd}_{43} \mathrm{Cu}_{27} \mathrm{Ni}_{10} \mathrm{P}_{20}$ bulk metallic glass. Sci Rep 2017; 11: 7989-7996.

[5] G.L Yang, X. Lin, F.C. Liu, et al. Laser solid forming Zr-based bulk metallic glass. Intermetallics 2012; 22: 110-115.

[6] J.H. Kim. Weldability of $\mathrm{Cu}_{54} \mathrm{Zr}_{22} \mathrm{Ti}_{18} \mathrm{Ni}_{6}$ bulk metallic glass by ultrasonic welding processing. Mater. Lett. 130 (2014) 160-163.

[7] M.Q. Jiang, B.M. Huang, Z.J. Jiang, et al. Joining of bulk metallic glass to brass by thick-walled cylinder explosion. Scr Mater 2015; 97: 17-20.

[8] Z. Jamili-Shirvan, M. Haddad-Sabzevar, J. Vahdati-Khaki, et al. Microstructure characterization and mechanical properties of Ti-based bulk metallic glass joints prepared with friction stir spot welding process. Mater Des 2016; 100: 120-131.

[9] S.F. Guo, K.C. Chan, Z.Q. Zhu, et al. Microstructure and tensile behavior of small scale resistance spot welded sandwich bulk metallic glasses. J Non-Cryst Solids. 2016; 446: 300-306.

[10]M. Pakdila, G. Çam, M. Koçak, et al. Microstructural and mechanical characterization of laser beam welded AA6056 Al-alloy. Mater. Sci. Eng. A 528 (2011) 7350-7356.

[11]Y. Yokoyama, N. Abe, K. Fukaura, et al. Electron beam welding of $\mathrm{Zr}_{50} \mathrm{Cu}_{30} \mathrm{Ni}_{10} \mathrm{Al}_{10}$ bulk glassy alloys. Mater Sci Eng A 2004; 375-377:422-426.

[12]Y. Kawahito, T. Terajima, H. Kimura, et al. High-power fiber laser welding and its application to metallic glass $\mathrm{Zr}_{55} \mathrm{Al}_{10} \mathrm{Ni}_{5} \mathrm{Cu}_{30}$. Mater Sci Eng B 2008; 148: 105-109.

[13]G. Wang, Y.J. Huang, M. Shagiev, et al. Laser welding of $\mathrm{Ti}_{40} \mathrm{Zr}_{25} \mathrm{Ni}_{3} \mathrm{Cu}_{12} \mathrm{Be}_{20}$ bulk metallic glass. Mater Sci Eng A 2012; 541: 33-37.

[14]T. Tsumaura, S. Hamada, H. Kimura, A. Inoue, K. Nakata. Dissimilar lap welding of Ni-based metallic glass and stainless steel foil by fiber laser beam. Transaction of JWRI, 2011; 40: 45-49. 
[15]B. Chen, T.L. Shi, M. Li, et al. Crystallization of $\mathrm{Zr}_{55} \mathrm{Al}_{10} \mathrm{Ni}_{5} \mathrm{Cu}_{30}$ bulk metallic glass in laser welding: simulation and experiment. Adv Eng Mater 2015; 17 : 483-450.

[16]H.Q. Sun, K.M. Flores. Spherulitic crystallization behavior of a metallic glass at high heating rates. Intermetallics 2011; 19: 1538-1545.

[17]Y.Z Lu, H. Zhang, H.G. Li, et al. Crystallization prediction on laser three-dimensional printing of Zr-based bulk metallic glass. J Non-Cryst Solids 2017; 461: 12-17.

[18]Q. Wang, Y.H. Zhang. Numerical simulation on electron beam welding temperature field of heat-resisting super-alloy. Transactions of the China Welding Institution, 2007, 28(6):97-100.

[19]D. Rosenthal. Mathematical theory of heat distribution during welding and cutting. Welding J. 1941; 20: 220-234.

[20]G. Wang, Y.J. Huang, J. Shen, et al. Laser welding behavior of TiZrNiCuBe bulk metallic glass and numerical simulation of temperature fields. Rare Metal Mater Eng 2014; 43: 2713-2718.

[21]Y.J. Huang, J. Shen, J.J.J. Chen, et al. Critical cooling rate and thermal stability for a Ti-Zr-Ni-Cu-Be metallic glass. J. Alloys. Compd. 477 (2009) 920-924.

[22]A. Inoue, Y. Yokoyama, Y. Shinohara. Preparation of bulk Zr-based amorphous alloys by a zone melting method. Mater Trans JIM 1994; 35: 923-926.

[23]Y. Yokoyama, A. Inoue. Solidification condition of bulk glassy $\mathrm{Zr}_{60} \mathrm{Al}_{10} \mathrm{Ni}_{10} \mathrm{Cu}_{15} \mathrm{Pd}_{5}$ alloy by unidirectional arc melting. Mater Trans JIM 1995; 36: 1398-1402.

[24]A. Inoue, Y. Shinohara, Y. Yokoyama, et al. Solidification analyses of bulky $\mathrm{Zr}_{60} \mathrm{Al}_{10} \mathrm{Ni}_{10} \mathrm{Cu}_{15} \mathrm{Pd}_{5}$ glass produced by casting into wedge-shape copper mold. Mater Trans JIM 1995; 36: 1276-1281.

[25]A.J. Drehman, A.L. Greer. Kinetics of crystal nucleation and growth in $\mathrm{Pd}_{40} \mathrm{Ni}_{40} \mathrm{P}_{20}$ glass. Acta Metall 1984, 32(3): 323-332.

[26]N. Nishiyama, A. Inoue. Supercooling investigations and critical cooling rate for glass formation in Pd-Cu-Ni-P alloy. Acta Mater 1999; 47: 1487-1495.

[27]A. Gebert, J. Eckert, L. Schultz. Effect of oxygen on phase formation and thermal stability of slowly cooled $\mathrm{Zr}_{65} \mathrm{Al}_{7.5} \mathrm{Cu}_{17.5} \mathrm{Ni}_{10}$ metallic glass. Acta Mater 1998; 46: 5475-5482.

[28]C.T. Liu, M.F. Chisholm, M.K. Miller. Oxygen impurity and micro-alloying effect in a Zr-based bulk metallic glass alloy. Intermetallics. 2002; 10: 1105-1112.

[29]H.F. Kissinger, Reaction kinetics in differential thermal analysis. Anal Chem 1957; 29: 1702-1706.

[30]D.R. Uhlmann. A kinetic treatment of glass formation, J Non-Cryst Solids 1972; 7:337. 
[31]P.I.K. Onorato, D.R. Uhlmann. Nucleating heterogeneities and glass formation. J. Non-Cryst. Solids. 22(1976) 367.

[32]C. A. Angell. Formation of glasses from liquids and biopolymers. Sci 1995; 267: 1924-1935.

[33]G. Wang, Y.J. Huang, D. Makhanlall, et al. Friction joining of $\mathrm{Ti}_{40} \mathrm{Zr}_{25} \mathrm{Ni}_{3} \mathrm{Cu}_{12} \mathrm{Be}_{20}$ bulk metallic glass. J Mater Process Tech 2012; 212: 1850-1855.

[34]J. Schroers, W.L. Johnson. Crystallization of $\mathrm{Zr}_{41} \mathrm{Ti}_{14} \mathrm{Cu}_{12} \mathrm{Ni}_{10} \mathrm{Be}_{23}$. Mater. Tran. JIM 2000; 41: 1530-1537.

[35]G. Wang. Welding behaviors of a TiZrNiCuBe bulk metallic glass, Harbin Institute of Technology, 2012, p. 56.

[36]M. Avrami, Kinetics of phase change III: granulation, phase change, and microstructure. J Chem Phys 1941; 9:177-184.

[37]M. Yamasaki, S. Kagao, Y. Kawamura, et al. Thermal diffusivity and conductivity of supercooled liquid in $\mathrm{Zr}_{41} \mathrm{Ti}_{14} \mathrm{Cu}_{12} \mathrm{Ni}_{10} \mathrm{Be}_{23}$ metallic glass. Appl Phys Lett 2004; 84: 4653-4655.

[38]M. Yamasaki, S. Kagao, Y. Kawamura. Thermal diffusivity and conductivity of $\mathrm{Zr}_{55} \mathrm{Al}_{10} \mathrm{Ni}_{5} \mathrm{Cu}_{30}$ bulk metallic glass. Scr Mater 2005; 5: 63-67. 
Figure Captions
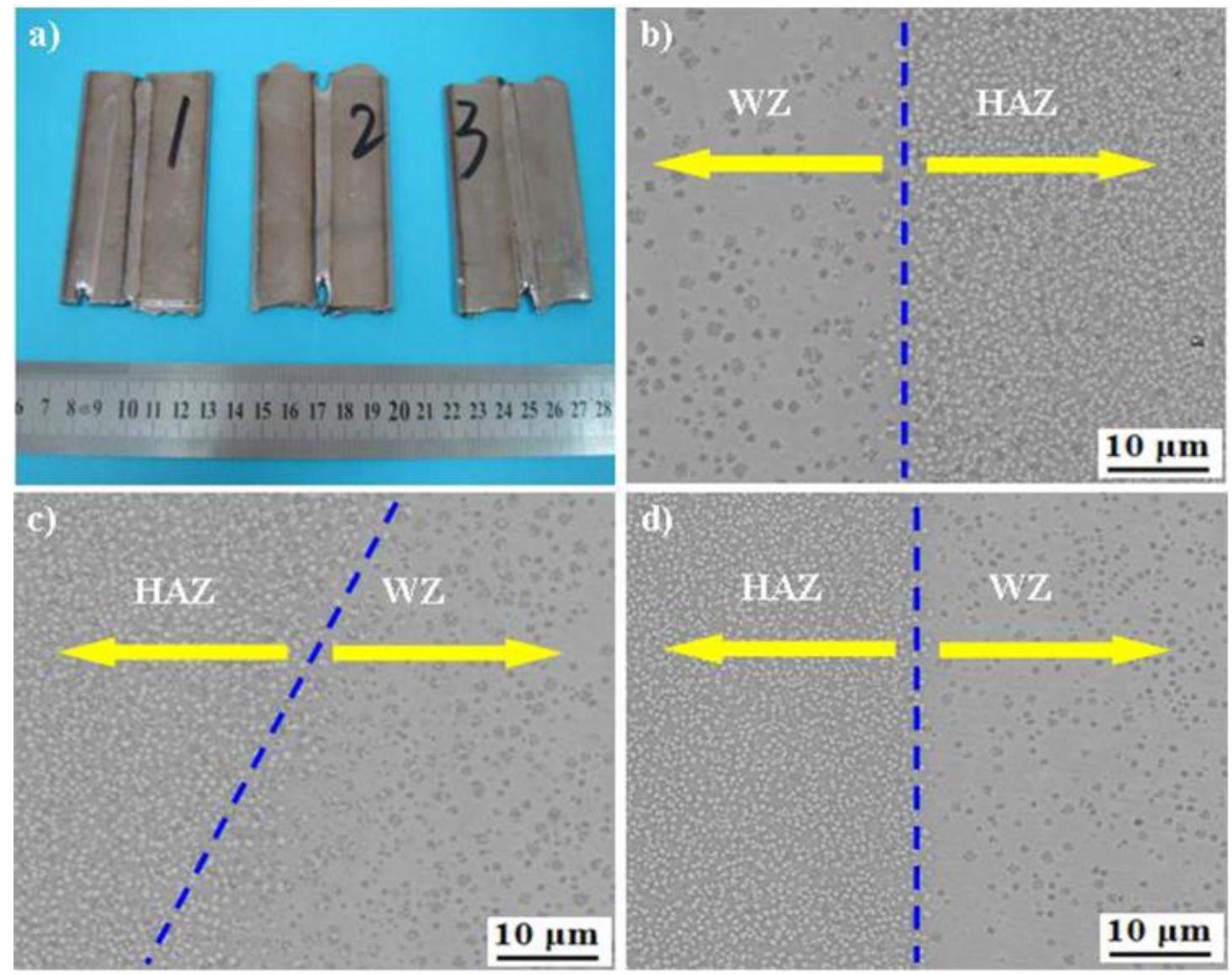

Fig. 1 a) Outer appearance of welded samples and SEM images of fusion zone in welded Ti-based BMG joint with different welding speeds: (b) $28 \mathrm{~mm} / \mathrm{min}$, (c) 32 $\mathrm{mm} / \mathrm{min}$, and (d) $34 \mathrm{~mm} / \mathrm{min}$
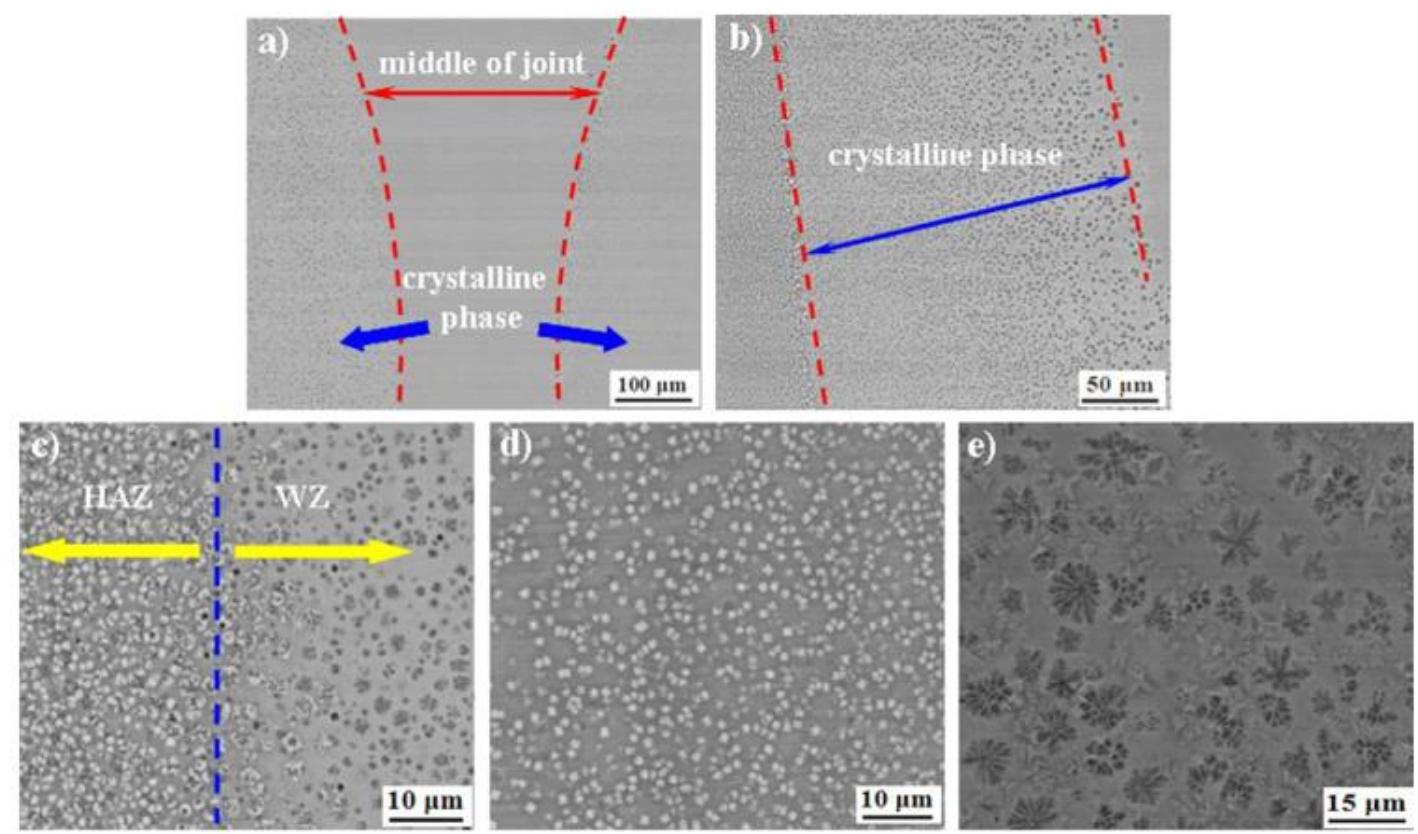

Fig. 2 SEM images of welded Ti-based joint with a welding speed of $34 \mathrm{~mm} / \mathrm{s}$ : a) middle of the weld, b) WZ, c) fusion zone, d) HAZ, and e) magnification of WZ 

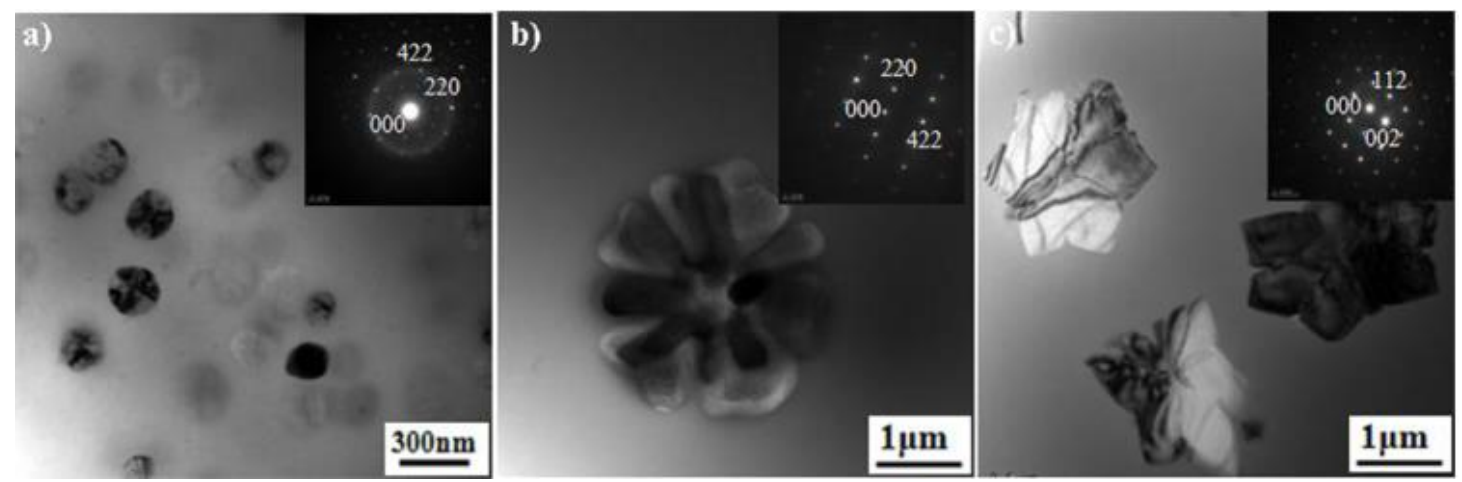

Fig.3 TEM images and corresponding SAED patterns of crystalline phases in a) middle of joint, b) WZ, and c) HAZ with a welding speed of $34 \mathrm{~mm} / \mathrm{s}$

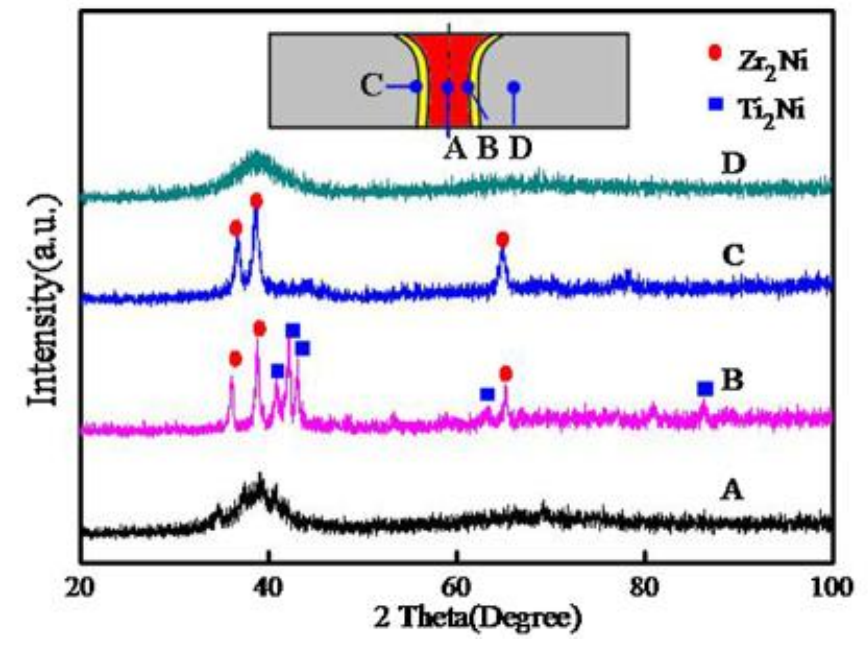

Fig.4 Micro-XRD patterns of welded Ti-based joint at different zone
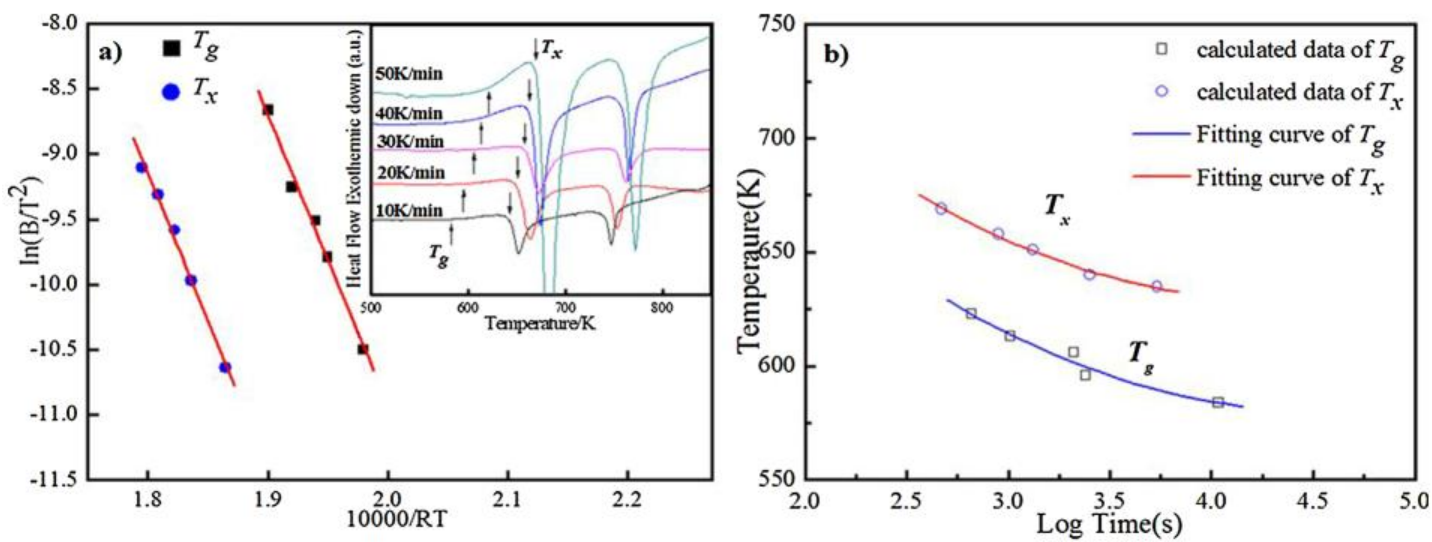

Fig.5 a) Kissinger plots for the $T_{g}$ and $T_{x}$, inset showing DSC curves with different heating rate and $b$ ) continuous heating transformation curve obtained from the Eqs.5 and 6. 

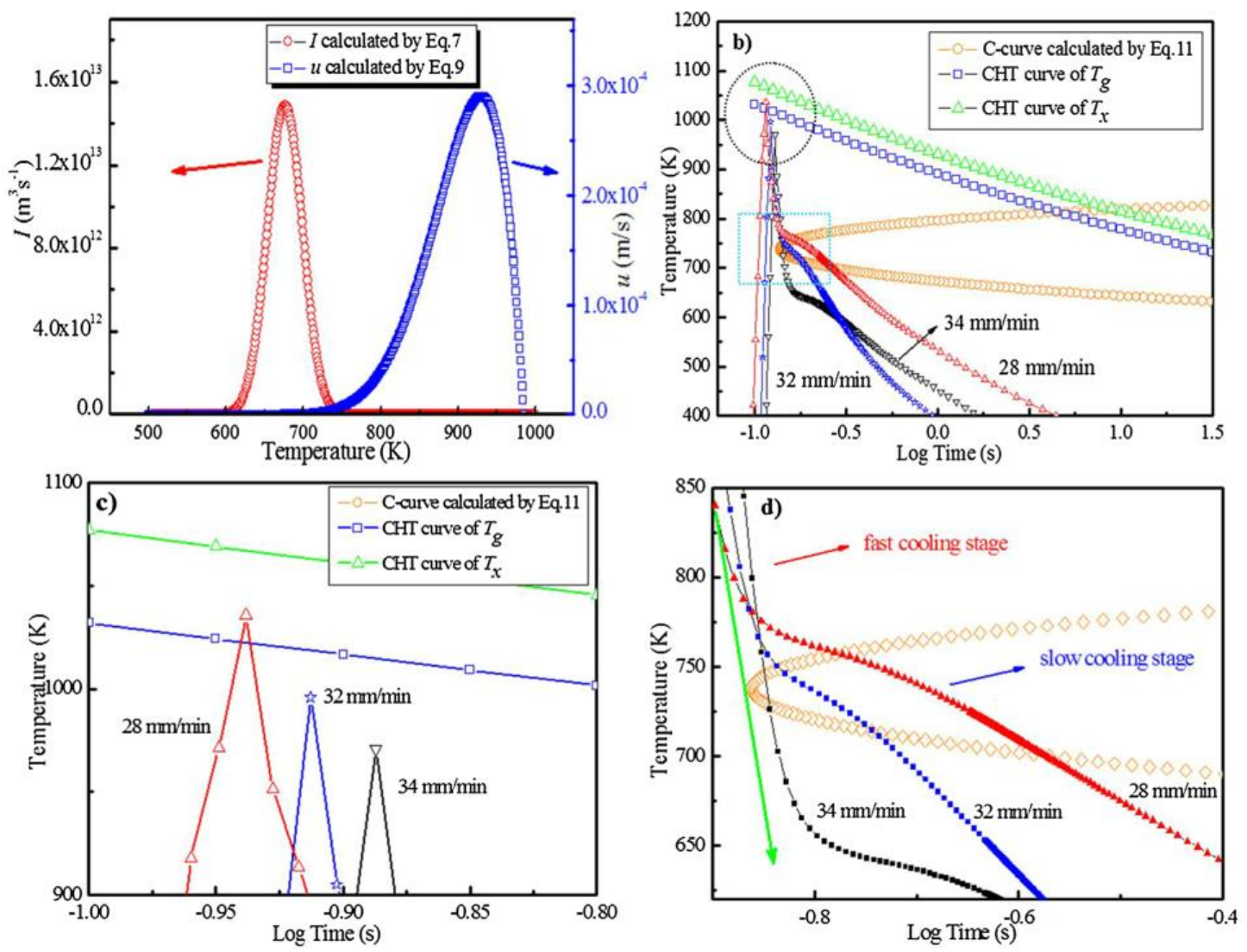

Fig.6 a) calculated nucleation frequency $(I)$ and growth rate $(u)$, b) calculated C-curve and thermal cycle curves, c) and d) magnification image from Fig.6b as indicated by circle and frame 